\title{
Dose response to inhaled salbutamol in chronic obstructive airways disease
}

\author{
C. Teale, J.F.J. Morrison, R.L. Page and S.B. Pearson \\ Pulmonary Function Laboratory, Killingbeck Hospital, York Road, Leeds LS14 6UQ, UK
}

\begin{abstract}
Summary: High dose inhaled salbutamol is increasingly used in the management of chronic obstructive airways disease. To determine the range of doses to achieve optimal bronchodilatation and the proportion of patients requiring high dose therapy we have studied 23 patients with chronic obstructive airways disease. Cumulative dose responses were measured to six incremental doses of salbutamol (0.2 to $1.2 \mathrm{mg}$ ) delivered by metered dose inhaler. Results were analysed by polynomial regression to calculate the smallest dose required to produce $90 \%$ maximal bronchodilatation in each patient. While $5 / 23(22 \%)$ required $>1$ mg the majority, $14 / 23$ (61\%), achieved $90 \%$ maximal bronchodilatation with salbutamol $0.6 \mathrm{mg}$ or less. The 8 patients with severe airflow limitation $\left(\mathrm{FEV}_{1} \leqslant 1\right.$ litre) showed a similar pattern of response.

We conclude that in chronic obstructive airways disease there are wide individual variations in the dose of inhaled salbutamol producing $90 \%$ maximal bronchodilatation with only a minority requiring high dose therapy.
\end{abstract}

\section{Introduction}

Concern has been expressed over the 'nebulizer epidemic,' but despite this, increasing numbers of patients are being treated with high dose nebulized beta-2 agonists with potential risks from side effects, possible delay in admission to hospital during an acute exacerbation and higher costs. ${ }^{1}$ Patients with severe, largely irreversible airflow limitation form a major group where nebulizer prescriptions are rising rapidly, probably because other therapeutic possibilities are limited.

Starting patients on nebulized salbutamol usually involves an increase in dose from $200 \mu \mathrm{g}$ by metered dose inhaler (MDI) to $2.5-5 \mathrm{mg}$ by nebulizer, a 12.5-25-fold increase in dose; whether such large doses are justified is questionable and the proportion of patients with chronic obstructive airways disease (COAD) who require doses of salbutamol of greater than $1 \mathrm{mg}$ to achieve optimal bronchodilatation is unknown. In an open study of 23 patients with COAD, cumulative dose responses to salbutamol have been measured to determine the range of doses required to produce near maximal bronchodilatation and the proportion of such patients who need high dose therapy to achieve this.

Correspondence: C. Teale, M.R.C.P.

Accepted: 28 February 1991

\section{Methods}

We studied 23 subjects with stable COAD. All had persistent symptoms for at least 2 years despite the use of standard doses of bronchodilators from a metered dose inhaler and were being assessed with a view to optimizing their dose. All showed less than $20 \%$ improvement in forced expiratory volume in the first second $\left(\mathrm{FEV}_{1}\right)$ following salbutamol $200 \mu \mathrm{g}$ ( 2 puffs by MDI). Inhaled bronchodilators were omitted for 12 hours before each study. Baseline $\mathrm{FEV}_{1}$ was recorded as the best of 9 blows over 1 hour, subjects then took salbutamol $0.2 \mathrm{mg}$ by MDI and FEV $_{1}$ (best of three) was measured 15 minutes later. The procedure was repeated to give cumulative doses of $0.2,0.4,0.6,0.8,1.0$ and $1.2 \mathrm{mg}$. All inhaler usage was supervised using a standard technique. Each dose response curve was analysed by polynomial regression to calculate maximal bronchodilatation and the smallest dose of salbutamol required to produce $90 \%$ maximal bronchodilatation. Changes in mean $\mathrm{FEV}_{1}$ were analysed by paired $t$-tests.

\section{Results}

Patients had a mean age of 56 years (range 38-82 years) and mean FEV 1 of 1.6 litres (range 0.5-2.9 litres). Table I shows the mean baseline FEV 1 was 1.63 litres which rose to a plateau of 2.00 litres with cumulative doses of salbutamol of 1.0 and $1.2 \mathrm{mg}$. Cumulative doses of $0.2,0.4$ and $0.6 \mathrm{mg}$ salbuta- 
Table I Dose response to inhaled salbutamol and minimal dose of salbutamol to produce $90 \%$ maximal bronchodilatation in 23 subjects with COAD

\begin{tabular}{|c|c|c|c|c|c|c|}
\hline \multirow{2}{*}{$\begin{array}{cl}\begin{array}{c}\text { Dose salbutamol } \\
\text { (mg) }\end{array} & \\
0 & \text { (baseline) }\end{array}$} & \multicolumn{2}{|c|}{$\begin{array}{c}\text { Mean FEV litres } \\
\text { (s.e.m.) }\end{array}$} & \multicolumn{4}{|c|}{$\begin{array}{l}\text { Number of subjects (\%) } \\
\text { achieving } 90 \% \text { maximal bronchodilatation }\end{array}$} \\
\hline & 1.63 & $(0.16)$ & - & - & - & - \\
\hline 0.2 & 1.78 & $(0.18)$ & 1 & (13) & 2 & (9) \\
\hline 0.4 & 1.90 & $(0.19)$ & 3 & (38) & 5 & (22) \\
\hline 0.6 & 1.95 & $(0.20)$ & 2 & (25) & 7 & (30) \\
\hline 0.8 & 1.97 & $(0.21)$ & 0 & (0) & 2 & (9) \\
\hline 1.0 & 2.00 & $(0.22)$ & 0 & (0) & 2 & (9) \\
\hline 1.2 & 2.00 & $(0.22)$ & 0 & (0) & 2 & (9) \\
\hline$>1.2$ & - & - & 2 & (25) & 3 & (13) \\
\hline
\end{tabular}

mol all produced highly significant improvements in mean $\mathrm{FEV}_{1}$ compared to the response to the previous dose $(P<0.01)$ but further increases in mean $F E V_{1}$ with higher doses of salbutamol failed to achieve significance (paired $t$-test between FEV after $0.6 \mathrm{mg}$ salbutamol and $1.2 \mathrm{mg}$ salbutamol $P>0.2$ ).

Table I also shows the numbers of subjects achieving $90 \%$ of maximal bronchodilatation with each cumulative dose of salbutamol. It can be seen that there were wide individual variations in the cumulative dose required to produce $90 \%$ maximal bronchodilatation and while $5 / 23(22 \%)$ required more than $1.0 \mathrm{mg}$ the majority $14 / 23$ (61\%) achieved $90 \%$ maximal bronchodilatation with salbutamol $0.6 \mathrm{mg}$ or less. Analysis of the 8 subjects with a baseline $\mathrm{FEV}_{1}$ of 1 litre or less showed a similar pattern of response with only two requiring $>1 \mathrm{mg}$ and the majority $6 / 8$ achieving $90 \%$ maximal bronchodilatation with salbutamol $0.6 \mathrm{mg}$ or less.

\section{Discussion}

These results suggest that most patients with COAD, irrespective of the severity of their disease, achieve $90 \%$ maximal bronchodilatation with modest doses of salbutamol (up to $0.6 \mathrm{mg}$ or 6 puffs by MDI) with only a minority gaining additional bronchodilatation from doses of greater than $1 \mathrm{mg}$.

This is the first dose-response study to determine the proportion of patients who achieve 'optimal' bronchodilatation with modest doses of inhaled beta-2 agonists in COAD. A number of authors have examined dose responses to beta- 2 agonists in asthma, although all have studied only small numbers of subjects. Barnes and Pride reported similar results in asthma with $7 / 8$ subjects achieving maximal bronchodilatation with a cumulative dose of salbutamol of less than $1 \mathrm{mg} .{ }^{2}$ However, other studies in asthma have suggested that cumulative doses of greater than $2 \mathrm{mg}$ salbutamol ${ }^{3}$ or $2-5 \mathrm{mg}$ terbutaline $e^{4}$ are required to achieve maximal bronchodilatation. Studies of subjects with COAD have tended to show only small improvements in mean parameters of airflow limitation with high dose compared to low dose inhaled beta- 2 agonists although higher doses may have a longer duration of effect. ${ }^{5-8}$

A number of points need to be considered in assessing these findings. First, only a minority of our patients had severe airflow limitation $\left(\mathrm{FEV}_{1}\right.$ $\leqslant 1$ litre). Responses of these patients were similar to the group as a whole although, with the possibility of type- 2 error in comparing two small groups, caution should be observed in extrapolating to a general population of patients with COAD. Secondly, the choice of $90 \%$ maximal bronchodilatation as 'optimal' was arbitrary but is probably a reasonable response to try to achieve in these patients since further bronchodilatation requires disproportionately large increases in dose given the shape of the dose response curve. Thirdly, the maximum dose of salbutamol at $1.2 \mathrm{mg}$ was lower than used in some studies; however, mean response had plateaued at $1.0 \mathrm{mg}$ and polynomial regression analysis allowed us to determine maximal bronchodilatation in all subjects. Fourthly, cumulative responses will tend to be greater than response to a single dose because initial bronchodilatation may lead to a more distal subsequent drug penetration;' patients may therefore benefit from slightly higher doses when taking this in a single administration. Fifthly, duration of response, which may increase with dose, was not assessed; $;, 8$ lower doses may require more frequent administration. Finally, although laboratory tests of short term reversibility have been advocated in selecting patients for a home nebulizer, ${ }^{10}$ recent work suggests that they may be poor predictors of long term response. ${ }^{11}$ Further studies examining 
responses to low and high bronchodilators compared to long term response to a home nebulizer would be of interest.

In conclusion, there are wide individual variations in the dose of inhaled salbutamol required to

\section{References}

1. Editorial. The nebuliser epidemic. Lancet 1984, ii: 789-790.

2. Barnes, P.J. \& Pride, N.B. Dose response curves to inhaled beta-adrenoceptor agonists in normal and asthmatic subjects. Br J Clin Pharmacol 1983, 15: 677-682.

3. Lipworth, B.J., Clark, R.A., Dhillon, D.P., Brown, R.A. \& McDevitt, D.G. Beta-adrenoceptor responses to high doses of inhaled salbutamol in bronchial asthma. $\mathrm{Br} J$ Clin Pharmacol 1988, 26: 527-533.

4. Prior, J.G. \& Cochrane, G.M. Assessment of optimum dose of inhaled terbutaline in patients with chronic asthma: the use of simple cumulative dose response curves. $\mathrm{Br} J$ Dis Chest 1982, 76: 266-268.

5. Connellan, S.J. \& Gough, S.E. The effects of nebulised salbutamol on lung function and exercise tolerance in patients with severe airflow obstruction. Br J Dis Chest 1982, 76: $135-142$.

6. Jenkins, S.C. \& Moxham, J. High dose salbutamol in chronic bronchitis: comparison of $400 \mathrm{mcg}, 1 \mathrm{mg}, 1.6 \mathrm{mg}$ and $2 \mathrm{mg}$ and placebo delivered by rotahaler. $B r J$ Dis Chest 1987, 81: 242-247.

achieve $90 \%$ maximal bronchodilatation in patients with COAD. Only a minority require the high doses of salbutamol delivered by nebulizer; doseresponse studies may be of benefit in identifying such patients.

7. Vathenen, A.S., Britton, J.R., Ebden, P., Cookson, J.B., Wharrad, H.J. \& Tattersfield, A.E. High dose inhaled albuterol in severe chronic airflow limitation. Am Rev Respir Dis 1988, 138: 850-855.

8. Assoufi, B.K. \& Hodson, M.E. High dose salbutamol in chronic airflow obstruction: comparison of nebuliser with Rotacaps. Resp Med 1989, 83: 415-420.

9. Britton, J. \& Tattersfield, A.E. Comparison of cumulative and non-cumulative techniques to measure dose response curves for beta-agonists in patients with asthma. Thorax 1984, 39: 597-599.

10. Cochrane, G.M., Prior, G.J. \& Rees, P.J. Home nebulisers for airflow limitation. $\mathrm{Br}$ Med J 1985, 290: 1608-1609.

11. O’Driscoll, B.R., Kay, E.A., Taylor, R.J. \& Bernstein, A. Home nebulisers: can optimal therapy be predicted by laboratory studies? Resp Med 1990, 84: 471-477. 